Open Access

\title{
Comparison of video demonstrations and bedside tutorials for teaching paediatric clinical skills to large groups of medical students in resource-constrained settings
}

Ann George 1* $^{*}$, Duane Blaauw², Lionel Green-Thompson ${ }^{3,6}$, Christina Hajinicolaou ${ }^{4}$, Nilesh Lala ${ }^{4}$, Kiran Parbhoo ${ }^{4}$, John Rodda ${ }^{4}$, Sithembiso Velaphi ${ }^{4}$, Udai Kala ${ }^{4}$, Preeteeben Vallabh ${ }^{4}$, Ziyaad Dangor ${ }^{4}$ and Sanjay G. Lala ${ }^{4,5}$

\author{
* Correspondence: Ann.George@ \\ wits.ac.za \\ ${ }^{1}$ Centre for Health Science \\ Education, Faculty of Health \\ Sciences, University of the \\ Witwatersrand, 29 Princess of Wales \\ Terrace, Parktown, Johannesburg \\ 2193, South Africa \\ Full list of author information is \\ available at the end of the article
}

\begin{abstract}
Videos are increasingly being used for teaching clinical skills in medical education. However, most reports on the effectiveness and benefits of videos in medical teaching have come from developed countries. Resource constraints in South African academic hospitals, together with increasing numbers, may apply pressure on the standard of clinical teaching. This study investigated the potential for using video demonstrations to replace the bedside teaching of introductory paediatric clinical examination skills to large groups of medical students. Sixty medical students were randomised to an experimental group that watched a video of a paediatric abdominal examination or to a control group that received a bedside tutorial on the same topic. Immediately afterwards, experienced assessors observed and scored the students in a clinical examination. Data were analysed for the non-inferiority of the video group scores within a 10\% margin of the bedside group. Students' and clinician educators' perceptions of the two teaching methods and their views on how video instruction could be integrated into the clinical teaching programme were explored. Qualitative data were analysed thematically. The video teaching was non-inferior to the bedside teaching within the 10\% margin and did not significantly affect the pass/fail or distinction rates. Students and clinician educators suggested that the videos be used for teaching basic concepts, allowing bedside tutorials to focus on applied learning. The findings have important implications for using video demonstrations to supplement the teaching of clinical skills to large groups of medical students across multiple variably-resourced settings.
\end{abstract}

Keywords: Video demonstrations, Clinical teaching (health professions), Teaching methods, Medical students

\section{Introduction}

The global pressure to increase the quantity, quality, and relevance of medical graduates (Frenk et al., 2010) poses a challenge to maintaining current clinical teaching practices. Increasing student-educator ratios in South African medical schools as a result of national imperatives for more health care graduates (South African National Department of Health, 2010) are adversely affecting clinical teaching. Furthermore, clinician 
educators' teaching time is being impacted by increasing patient loads (Coovadia, Jewkes, Barron, Sanders, \& McIntyre, 2009; Mayosi et al., 2009; 2014) and the number of educators is unlikely to increase because of "less economic resources available to fund higher education institutions" (Hornsby, Osman, \& De Matos-Ala, 2013, p. 10) in lowto middle- income countries. Undergraduate paediatric clinical training is further compromised by the lack of physical space around the bedside in overcrowded wards and the impracticality of allowing large numbers of students to examine an infant or young child (Craze \& Hope, 2006). These challenges hamper the development of the essential clinical, problem-solving, and critical thinking skills required for competent medical graduates (Hornsby et al., 2013; Maudsley \& Strivens, 2000; McKeachie, 1980).

Clinical skills training involves the acquisition of both technical skills and non-technical skills. An example of a technical skill is conducting a physical examination while non-technical skills include communication and cognitive skills like clinical reasoning and decision-making (Hibbert et al., 2013; Michels, Evans, \& Blok, 2012). Video demonstrations may provide a" best practice exemplar" for the initial learning of clinical skills (Hibbert et al., 2013, p. 2). This initial demonstration of clinical skills forms the basis of the theory of acquiring skills. According to the social cognitive model of sequential skill acquisition (see Fig. 1), observing a skill being demonstrated by someone proficient in that skill is the first of four phases of learning, followed by imitating the behaviour, and eventually leading to the self-regulated performance of the behaviour (Schunk \& Zimmerman, 1997; Zimmerman \& Kitsantas, 2002). The first two phases are regarded as learning in a social context, which may lead to the self-directed practice of the skill (last two phases; see Fig. 1) (Schunk \& Zimmerman, 1997; Zimmerman \& Kitsantas, 2002). Observing a demonstration also forms the first step in Peyton's approach to teaching procedural and physical examination skills, which consists of the following steps (Lake \& Hamdorf, 2004; Walker \& Peyton, 1998):

- Demonstration: The tutor demonstrates the skill at a normal pace, without commentary.

- Deconstruction: The tutor demonstrates each procedural step while describing it.

- Comprehension: The student provides instructions, which the tutor then demonstrates.

- Performance: The student performs the skill while describing the steps.

Demonstrations are believed to be useful for providing an overview of the complete set of skills to be learned, especially when an overview is provided early in the learning process (Kneebone, 2005; Sadideen \& Kneebone, 2012; Singley \& Anderson, 1989), as evident in the models of how clinical skills are learned.

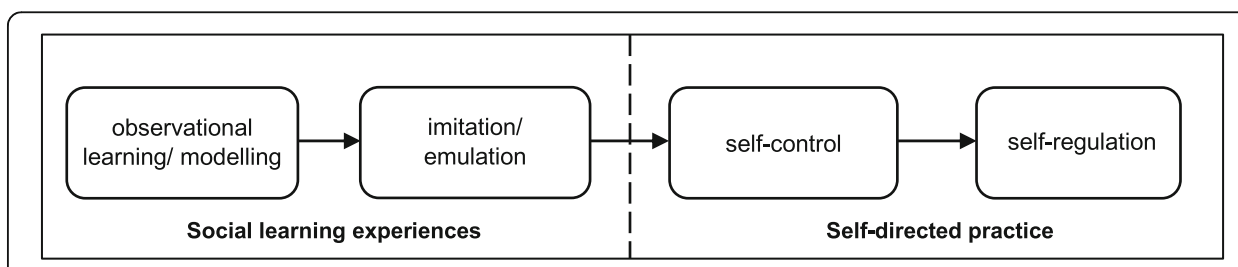

Fig. 1 Social cognitive model of sequential skill acquisition 
In addition to the benefits for learning clinical skills, video demonstrations have been shown to be useful in managing the limited time available for clinical teaching (Hoffman \& Donaldson, 2004; Hurtubise, Martin, Gilliland, \& Mahan, 2013; Jeffries, 2001; Knowles, Kinchington, Erwin, \& Peters, 2001; Schwerdtfeger et al., 2014), allowing more efficient utilisation of resources (Schwerdtfeger et al., 2014), and improving costefficiency (Hibbert et al., 2013; Wouters, Tabbers, \& Paas, 2007). The benefits of improving the efficiency of teaching and the utilisation of resources, and the cost efficiency, could be advantageous in resource-constrained settings in low- and middleincome countries. However, most reports on the use of videos have come from developed countries, with little evidence for whether videos improve the efficiency of clinical teaching in low- and middle-income countries.

Concerned about the prevailing resource constraints and the increasing student numbers (12-14 students per group compared to 6-8 students per group in earlier years), educators in the Department of Paediatric and Child Health at the Chris Hani Baragwanath Academic Hospital (CHBAH) in Johannesburg, an academic hospital affiliated with the University of the Witwatersrand, recorded videos demonstrating introductory paediatric clinical examination skills. These video demonstrations were intended to replace the bedside teaching of clinical skills. This study investigated whether video demonstrations were at least as good as (that is, not inferior to) the bedside teaching and explored medical students' and clinician educators' perceptions of the benefits and limitations of video teaching compared to bedside teaching.

\section{Methods}

\section{Study design}

This study adopted a pragmatic approach to the selection and combination of data collection methods and analysis strategies to address the research questions (Creswell, 2014; Johnson, Onwuegbuzie, \& Turner, 2007). The mixed methods design combined qualitative and quantitative methods to answer different research questions. Table 1 provides an overview of the data collection strategies employed in the study, in chronological order, and describes the sample, purpose, and type of data analysis used for each strategy.

CHBAH receives a group of approximately 20 medical students in their fifth (penultimate) year of study for 6 weeks of training in paediatric clinical skills (paediatric

Table 1 The research strategies, samples, and type of analysis used in the study

\begin{tabular}{|c|c|c|c|}
\hline Strategy & Sample & Purpose & $\begin{array}{l}\text { Analysis } \\
\text { type }\end{array}$ \\
\hline $\begin{array}{l}\text { Randomised } \\
\text { controlled } \\
\text { trial }\end{array}$ & $\begin{array}{l}\text { Convenience sample of } 60 \text { 5th year } \\
\text { medical students }\end{array}$ & $\begin{array}{l}\text { To compare students' performance when } \\
\text { conducting a clinical examination after } \\
\text { being taught either by video teaching or } \\
\text { bedside teaching }\end{array}$ & $\begin{array}{l}\text { Non- } \\
\text { inferiority } \\
\text { analysis }\end{array}$ \\
\hline $\begin{array}{l}\text { Focus group } \\
\text { discussions }\end{array}$ & $\begin{array}{l}\text { Purposive sample of five students per } \\
\text { intervention (video/ bedside teaching) } \\
\text { for each of three rounds of data } \\
\text { collection (six focus groups) }\end{array}$ & $\begin{array}{l}\text { To explore students' perceptions of the } \\
\text { advantages and disadvantages of video } \\
\text { instruction compared to bedside } \\
\text { teaching }\end{array}$ & $\begin{array}{l}\text { Thematic } \\
\text { analysis }\end{array}$ \\
\hline $\begin{array}{l}\text { Semi- } \\
\text { structured } \\
\text { interviews }\end{array}$ & $\begin{array}{l}\text { Purposive sample of five evaluators who } \\
\text { assessed the students as they conducted } \\
\text { a clinical examination }\end{array}$ & $\begin{array}{l}\text { To explore clinician educators' views of } \\
\text { the potential benefits or disadvantages of } \\
\text { introducing instructional videos into the } \\
\text { clinical training programme }\end{array}$ & $\begin{array}{l}\text { Thematic } \\
\text { analysis }\end{array}$ \\
\hline
\end{tabular}


rotation). There were three such paediatric rotations between February and May 2017, a total of $61^{1}$ students. Each group of students consists of self-selected pairs of clinical partners who would have received similar clinical training up to that point in their studies. To control for skills acquired during their pre-clinical training, consenting students were randomised by splitting the clinical pairs so that one partner was allocated to the video group and the other to the bedside teaching group. The 61 students reporting to CHBAH for paediatric training between February and May 2017 were eligible to participate in the study, 60 of them agreeing to participate and one declining. Figure 2 provides an overview of the design of the study. Each participating student provided written informed consent. The Human Research Ethics Committee (Medical) of the University of the Witwatersrand approved the study: clearance certificate M160739.

\section{Description of video demonstration and bedside teaching interventions}

For each of the three rounds of data collection, the video group $(n=10)$ watched a 20min video demonstration of a structured abdominal examination being conducted on a real patient (as opposed to a simulated one) by an experienced paediatric gastroenterologist. The patient's caregiver was present during the recording session, which took place in a facility separate to the general ward without other patients or healthcare professionals present. The infant did not necessarily exhibit any abdominal symptoms since the teaching session focused on the steps and sequence of the examination rather than on identifying pathology. The protocol for teaching the clinical examination focused on the domains of professionalism (for example, greeting the patient), physical examination skills (for example, inspecting the abdomen or examining the genitals) and how well the examination was structured (organisation).

For each round of data collection, the bedside group $(n=10)$ received a 25- to 30min tutorial at the bedside on how to conduct a structured abdominal examination, using a real patient. The same paediatric gastroenterologist conducted the three bedside tutorials using the same teaching protocol as for the video demonstration. The bedside tutorial was conducted in a quieter and more spacious facility than the general paediatric ward that is usually used for clinical teaching, to facilitate a better comparison of teaching methods. Similar to the video demonstration, the patients used for the bedside tutorial did not necessarily exhibit any abdominal symptoms.

\section{Randomised non-inferiority trial}

The hypothesis for the randomised control trial was that video teaching of the paediatric abdominal examination is not inferior to traditional bedside teaching regarding student performance in a clinical examination.

After the video and bedside teaching sessions, each student performed a 10-min structured clinical examination of an in-hospital patient (Fig. 2). The assessment team consisted of five paediatricians, each with 27-33 years of experience as clinician educators. Four assessors were used on each of the three rounds of data collection, according to availability (Fig. 2). Individual students were allocated at random to one of four

${ }^{1}$ Discordant numbers of students result from students repeating a clinical rotation. 


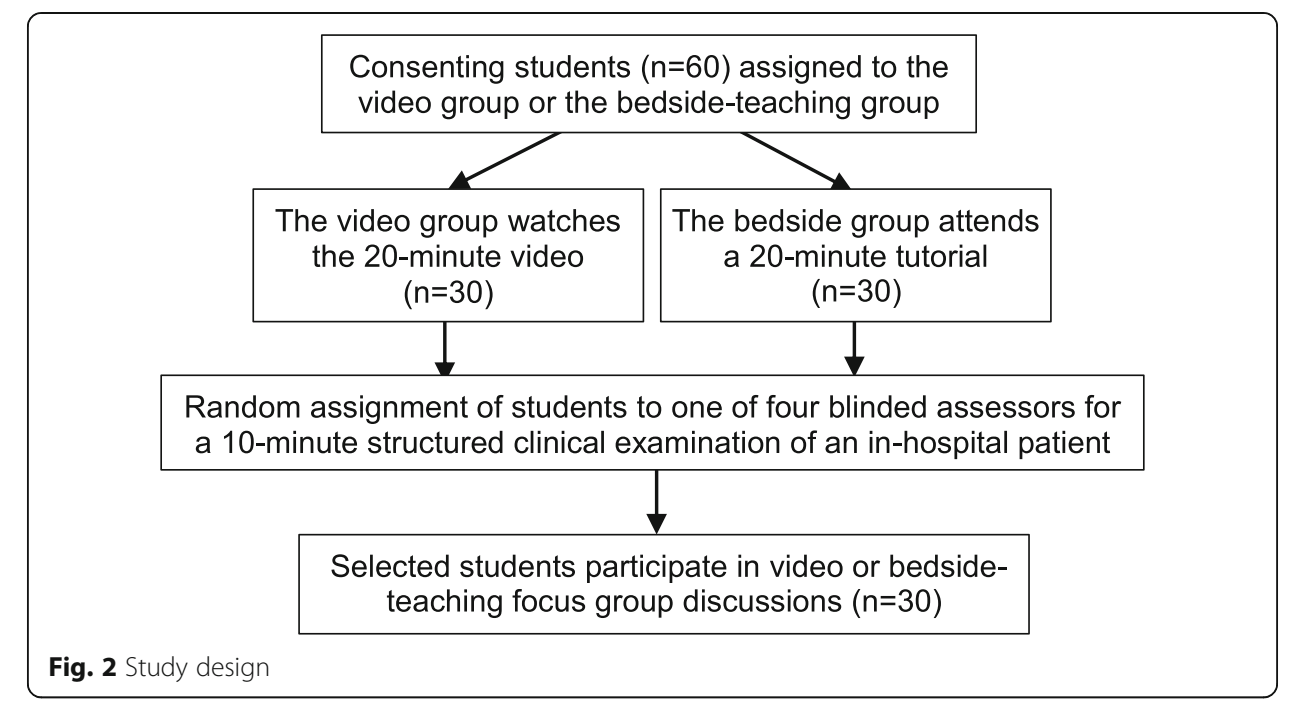

assessors. The assessment was blind, in that the assessors did not know which students had received video teaching and which had experienced bedside teaching.

The evaluation instrument assessed three domains (see Additional file 1: Assessment tool for clinical examination) according to the standard method of teaching and assessing the structured abdominal examination at Wits medical school. The main domain, Physical Examination skills, used a checklist of ten items, each scored on a scale of 1 to 5. The total of the score for the ten items was used to compare the scores for the bedside and video groups. The two other domains, Professionalism and Organisation/Efficiency, were each scored on a scale of 1-10. The assessors assigned an Overall Grade category, using a percentage range, to each student for the clinical examination. The assessors were briefed on how to use the evaluation instrument before the clinical examinations.

The required sample size for non-inferiority analysis (Piaggio, Elbourne, Altman, Pocock, \& Evans, 2006) was calculated using data from a pilot study conducted in August 2016. Assuming a mean score of $70 \%$ in the better group, a non-inferiority margin of $10 \%$, a standard deviation of $10 \%$ for both groups, $90 \%$ power, and a $95 \%$ confidence interval, we used the ssi module (Jones, 2010) for Stata (version 14.0) to calculate that at least 18 students were needed in each group (total $=36$ ). A non-inferiority margin of $10 \%$ (or a difference of 1 mark between the mean scores for the video and bedside teaching groups) was determined based on previous class marks for four paediatric teaching blocks for fifth-year students in 2015 and 2016. Given the average mark of 69.5\% for the four paediatric teaching blocks for fifth-year students in 2015 and 2016, and the pass mark of $60 \%$ used for clinical blocks, the assessors deemed a $10 \%$ (or 1mark) difference educationally important (Cook \& Hatala, 2015; Greene, Morland, Durkalski, \& Frueh, 2008; Tolsgaard \& Ringsted, 2014). Half-marks are not allocated in the clinical assessments, so a 1-mark difference was the smallest margin that would affect the number of students who pass or fail.

The scores for each of the three domains assessed in the clinical examination were converted to percentages for the analyses. For the Overall Grade category, the midpoint of the range for each symbol was converted to a percentage to enable a numerical comparison between the video and bedside groups. A statistical test was used to calculate 
the one-sided 95\% confidence interval of the difference between the two groups and was compared to the $10 \%$ non-inferiority margin decided by the paediatricians (Greene et al., 2008; Tolsgaard \& Ringsted, 2014). Linear regression was used to adjust for differences between the groups: age, previous academic performance based on examination scores obtained from the university's Unit for Undergraduate Medical Education, and any assessor effects. The robustness of the results was checked using a number of alternative specifications. The overall pass and failure rates for the two groups were compared using the chi-squared test for statistical differences. Finally, non-inferiority was checked using a two-sided confidence interval instead of one (Piaggio et al., 2006).

\section{Focus groups and semi-structured interviews}

For each of the three rounds of data collection, after the clinical examinations were completed, five of the ten students in each of the video and bedside teaching groups were invited to participate in separate focus group discussions for each intervention (see Fig. 2). The focus group discussions were conducted by a research assistant (with a Bachelor of Arts Honours degree) trained in conducting focus group interviews. Table 2 lists the questions asked in each focus group. Students in each group were initially asked similar questions designed to explore their perceptions of the teaching method they had received and to probe for their suggestions for improvements to that teaching method. Different focus questions were then asked of each group, based on the fact that the bedside groups had not watched the video, and the video groups had not experienced a 'live' bedside demonstration. The final question for the bedside groups honed in on whether students felt they would have derived similar benefits from the video demonstration compared to the bedside tutorial they had attended. The video groups were asked two final questions, focusing on, firstly, how they felt having access to video demonstrations could benefit their learning, and secondly, what they perceived were the limitations of video demonstrations for teaching clinical examination skills.

Semi-structured interviews were conducted with the five assessors after all three rounds of data collection had been completed. The assessors were asked about their clinical teaching experience, how their experiences of clinical teaching had changed over the time they had been teaching at $\mathrm{CHBAH}$, and how they felt about the use of video demonstrations for teaching clinical examination skills.

The focus group discussions and interviews were audio-recorded and transcribed verbatim. Thematic analysis (Braun \& Clarke, 2013) was used to analyse the transcripts.

Table 2 Focus group questions

\begin{tabular}{|c|c|}
\hline Bedside tutorial group & Video demonstration group \\
\hline $\begin{array}{l}\text { Did you find the bedside teaching useful? Which aspects } \\
\text { of bedside teaching were useful? }\end{array}$ & $\begin{array}{l}\text { What did you think of the video you just watched? } \\
\text { Which aspects were useful? }\end{array}$ \\
\hline $\begin{array}{l}\text { Which aspects do you think could have been done } \\
\text { better? }\end{array}$ & $\begin{array}{l}\text { Which aspects of the video could have been } \\
\text { improved? }\end{array}$ \\
\hline \multirow{2}{*}{$\begin{array}{l}\text { Do you think you would have derived the same benefits } \\
\text { from watching a video presentation instead of having } \\
\text { the bedside teaching? Please explain. }\end{array}$} & $\begin{array}{l}\text { In what ways do you think the video could be } \\
\text { useful for teaching clinical examination technique? }\end{array}$ \\
\hline & $\begin{array}{l}\text { Is there anything that you think could limit the } \\
\text { usefulness of a video for teaching clinical } \\
\text { examination techniques? }\end{array}$ \\
\hline
\end{tabular}


The patterns identified by open coding in the focus group and interview transcripts were clustered into themes and sub-themes, which were mapped to display the relationships between them (Braun \& Clarke, 2013). The thematic maps include frequency counts to show the extent of the themes and sub-themes identified (Fraenkel, Wallen, \& Hyun, 2012; Krippendorff, 2013), without implying that "numbers reveal the truth in the data" (Braun \& Clarke, 2013, p. 262). MAXQDA 2018 was used to manage the analysis (Creswell, 2014). Multiple coding involving the "cross checking of coding strategies and interpretation of data" (Barbour, 2001, p. 1116) by two researchers on the team was used to obtain different insights and perspectives on the data. Member checking (McMillan \& Schumacher, 2010) was used to check the accuracy of the interpretations of the interviews with the interviewed assessors to improve the credibility of the findings.

\section{Results}

Profiles of the video and bedside-teaching groups

Table 3 compares the students randomised to the video and bedside-teaching groups regarding age, gender, and academic performance in 2016. The differences were found not to be statistically significant. The comparisons of the number of students allocated to each assessor for the two groups was also not significantly different.

\section{Comparison of the scores for the students' clinical examinations, by group}

Table 4 reports the mean scores for the assessment of the students' clinical examination performance, by group. The mean scores for all measures assessed in the clinical examination, except for Professionalism, were lower for the video group, with wider variability.

Figure 3 shows the non-inferiority analysis. The mean difference and associated confidence interval were within the non-inferiority margin of $10 \%$ for all four measures assessed in the clinical examination performed by the students (Fig. 3). The difference between the means for the video and bedside groups was highest for the Efficiency domain $(-4.33 \%)$ followed by the Physical Examination domain $(-2.20 \%)$ and Professionalism $(-1.17 \%)$. The difference in the Overall Grade between the video and bedside groups was $-2.6 \%$ [one-sided 95\% CI: $-6.2--2.6$ ]. Adjusting the non-inferiority

Table 3 The mean characteristics of participants, by group $(n=60)$

\begin{tabular}{llll}
\hline & $\begin{array}{l}\text { Total }(n= \\
60)\end{array}$ & $\begin{array}{l}\text { Bedside teaching group } \\
(n=30)\end{array}$ & $\begin{array}{l}\text { Video group }(n= \\
30)\end{array}$ \\
\hline Sex (Female) (number +\%) & $38(63.3 \%)$ & $20(66.7 \%)$ & $18(60 \%)$ \\
Age (mean \pm SD) & $24.1 \pm 3.2$ & $23.8 \pm 1.6$ & $24.40 \pm 4.3$ \\
$\begin{array}{l}\text { Examination scores in the previous year } \\
\text { (mean } \pm \text { SD) }\end{array}$ & $74.4 \% \pm 6.8$ & $74.6 \% \pm 5.7$ & $74.3 \% \pm 7.8$ \\
Assessors (number of students + \%) & & & \\
Assessor 1 & $15(25.0 \%)$ & $7(23.0 \%)$ & $8(26.7 \%)$ \\
Assessor 2 & $10(16.7 \%)$ & $6(20.0 \%)$ & $4(13.3 \%)$ \\
Assessor 3 & $10(16.7 \%)$ & $4(13.3 \%)$ & $6(20.0 \%)$ \\
Assessor 4 & $15(25.0 \%)$ & $8(26.7 \%)$ & $7(23.0 \%)$ \\
Assessor 5 & $10(16.7 \%)$ & $5(16.7 \%)$ & $5(16.8 \%)$ \\
\hline
\end{tabular}


Table 4 Mean scores for the students' clinical examinations, by group $(n=60)$

\begin{tabular}{lll}
\hline & $\begin{array}{l}\text { Bedside teaching group }(n=30) \\
\text { Mean }(95 \% \mathrm{Cl})\end{array}$ & $\begin{array}{l}\text { Video group }(n=30) \\
\text { Mean }(95 \% \mathrm{Cl})\end{array}$ \\
\hline Physical examination score (\%) & $70.5(66.8-74.2)$ & $68.3(63.4-73.2)$ \\
Professionalism (\%) & $66.5(62.1-70.9)$ & $65.3(59.9-70.8)$ \\
Efficiency/Organisation (\%) & $69.3(66.8-71.9)$ & $65.0(61.5-68.5)$ \\
Overall Grade (\%) & $71.7(69.3-74.0)$ & $69.1(66.3-71.9)$ \\
\hline
\end{tabular}

analysis for age, gender, previous academic performance and assessors made no difference to the conclusions of the non-inferiority analysis. Lastly, non-inferiority analysis using the two-sided confidence interval did not change the overall results and study conclusions.

The mean difference and associated confidence interval were within the non-inferiority margin of $10 \%$ for all four measures assessed in the clinical examination performed by the students. The difference between the means for the video and bedside groups was highest for the Efficiency domain (-4.33\%) followed by the Physical Examination domain $(-2.20 \%)$ and Professionalism $(-1.17 \%)$. The difference in the Overall Grade between the video and bedside groups was $-2.6 \%$ [one-sided 95\% CI: $-6.2--2.6$ ] Adjusting the non-inferiority analysis for age, gender, previous academic performance and assessors made no difference to the conclusions of the non-inferiority analysis. The non-inferiority analysis using the two-sided confidence interval did not change the overall results and study conclusions.

Lastly, the proportion of fails $(<60 \%)$ and distinctions $(\geq 80 \%)$, based on the Overall Grade, was not significantly different between the two groups (Table 5 ).

\section{Student perceptions of the video demonstrations compared to bedside teaching}

In the focus group discussions, students were asked about the usefulness and limitations of the teaching method they had received. Open coding of the transcripts revealed the features of clinical teaching that students felt were important. Responses from the two groups were compared to identify themes describing the potential of video demonstrations to replace bedside teaching. The two themes identified (see Fig. 4) have been named to reflect the potential for video demonstrations to replace bedside teaching: Videos cannot replace bedside tutorials, and Videos could supplement bedside teaching.

Two sub-themes representing categories of video features were identified under the theme Videos cannot replace bedside tutorials. The main category was the lack of interpersonal interactions with tutors, peers, and patients (see Fig. 4). Students also valued learning from the mistakes made by their peers at the bedside (see Fig. 4). The other category under this theme was Videos do not engage students as much as bedside teaching.

Eight features of video demonstrations made up the theme Video demonstrations could supplement bedside teaching (see Fig. 4). The four most frequently mentioned features were that video demonstrations allow flexible access to the demonstration, offer better audio and visual features, tend to be better organised than bedside tutorials and are useful for providing the theory underpinning clinical skills. 


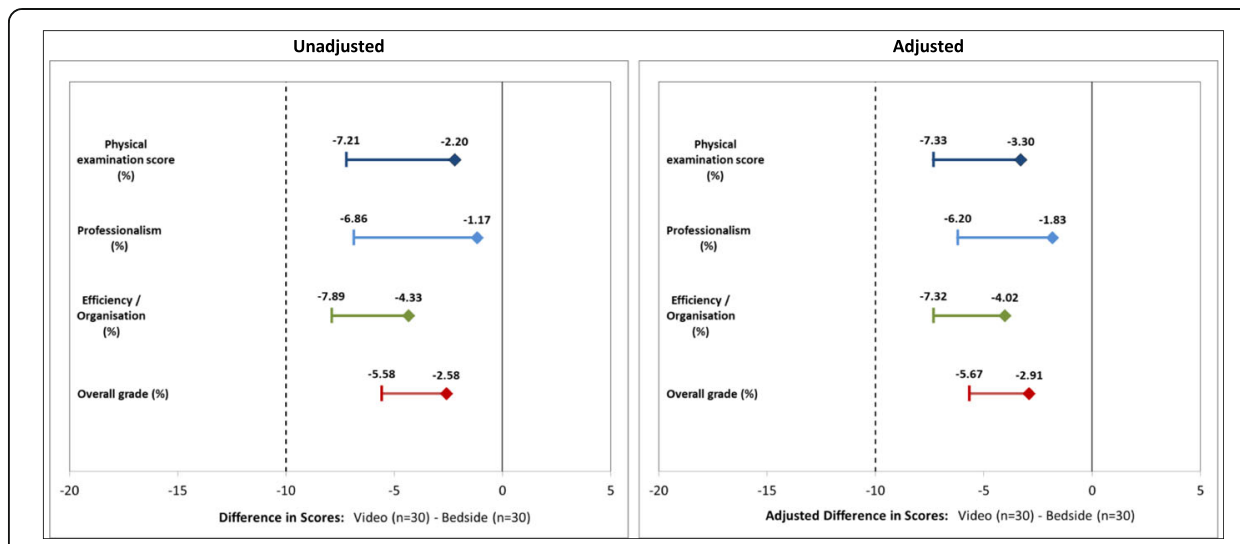

Fig. 3 Non-inferiority of clinical examination assessment scores between the video and bedside teaching groups. The diamonds represent the mean difference between the groups and the horizontal lines shows the one-sided confidence interval for non-inferiority. For all four criteria, the confidence interval is narrow enough to exclude an educationally important effect. The adjusted results show the mean difference adjusted for age, gender, previous academic performance, and evaluator

Students emphasised the benefit of videos allowing flexible access to clinical demonstrations (see Fig. 4). While students preferred that the videos be used with bedside teaching, there was no clear preference as to how the videos should be used. Some students suggested that it could be useful to watch the demonstrations before the tutorial while other students indicated that the videos would be a useful tool for revision. The second most frequently mentioned feature was the superior audio and visual features of videos (see Fig. 4), which were often mentioned in the context of the difficulties with seeing and hearing in large groups at the bedside. Students pointed out the benefits of the different camera angles and capability to zoom in on features possible in video recordings, which further enhanced the visual aspect.

The third most frequently mentioned feature was that video demonstrations tend to be better organised than bedside tutorials (see Fig. 4). A subtle difference emerged between videos being more 'systematic' than bedside teaching and video demonstrations offering 'standardised' teaching. 'Systematic' refers to the teaching being organised in an orderly manner, while 'standardised' suggests that the teaching is uniform across, for example, different teachers. Teaching can be standardised (uniform) without being systematic (organised in a logical fashion). Teaching can also be systematic (organised in a logical fashion) without being standardised (uniform). A video demonstration of a clinical examination is likely to contribute to both systematic and standardised teaching.

Another frequently mentioned feature was that students regard videos as useful for providing the theory (see Fig. 4). There was a distinction between how students perceived the roles of the video demonstrations and the bedside tutorials. The video demonstrations were regarded as useful for providing the theory (see Fig. 4), while the bedside tutorials allow for the application of that theory.

Table 5 Fails and distinctions, based on Overall Grade, by group $(n=60)$

\begin{tabular}{llll}
\hline & Bedside teaching group $(n=30)$ & Video group $(n=30)$ & $p$ value \\
\hline Fails $(<60 \%)$ & $4(13.3 \%)$ & $5(16.7 \%)$ & $0.718^{*}$ \\
Distinctions $(>80 \%)$ & $6(20.0 \%)$ & $5(16.7 \%)$ & $0.739^{*}$ \\
\hline
\end{tabular}

"Pearson's Chi-square test 


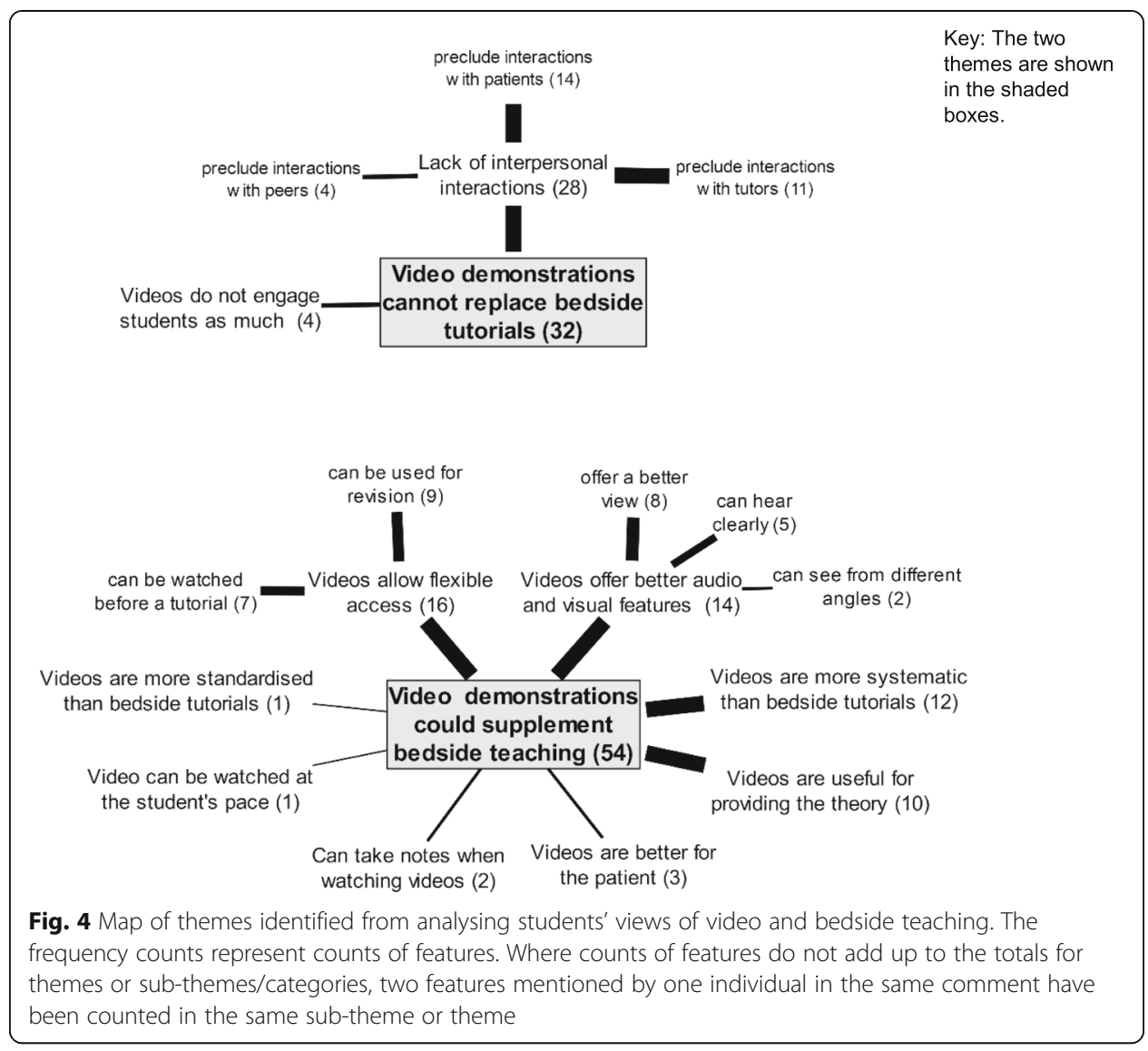

\section{Assessors' views on the video demonstrations compared to bedside teaching}

The five assessors (four males and one female) had been teaching clinical skills at CHBAH for between 16 and 33 years. None of the assessors had been involved in recording the video used in the study or had watched the video.

Figure 5 shows a map of the four themes identified from analysing the assessor interviews. The patterns highlighted in this analysis are those relating to the third sub-objective for the study, which was "To explore clinician educators' views of using video demonstrations for teaching clinical examination skills".

The assessors described six sub-themes or categories of factors that influenced their clinical teaching (see Factors affecting clinical teaching in Fig. 5), with the main factor being the impact of increasing student numbers.

Four categories were identified from assessors' comments about problems they encountered when teaching larger groups at the bedside (see Problems when teaching large groups in Fig. 5). The assessors' concerns centred around larger groups making it difficult for teachers to engage with individual students and to pay more attention to weaker or more reticent students.

The assessors suggested five types of interventions that could be implemented to address the problems experienced when teaching larger groups (see Interventions to cope with larger groups in Fig. 5). Video demonstrations were one of the ways assessors suggested of coping with larger groups without increases in staff numbers (see Fig. 5). The assessors regarded the feature that video demonstrations could provide the basic 


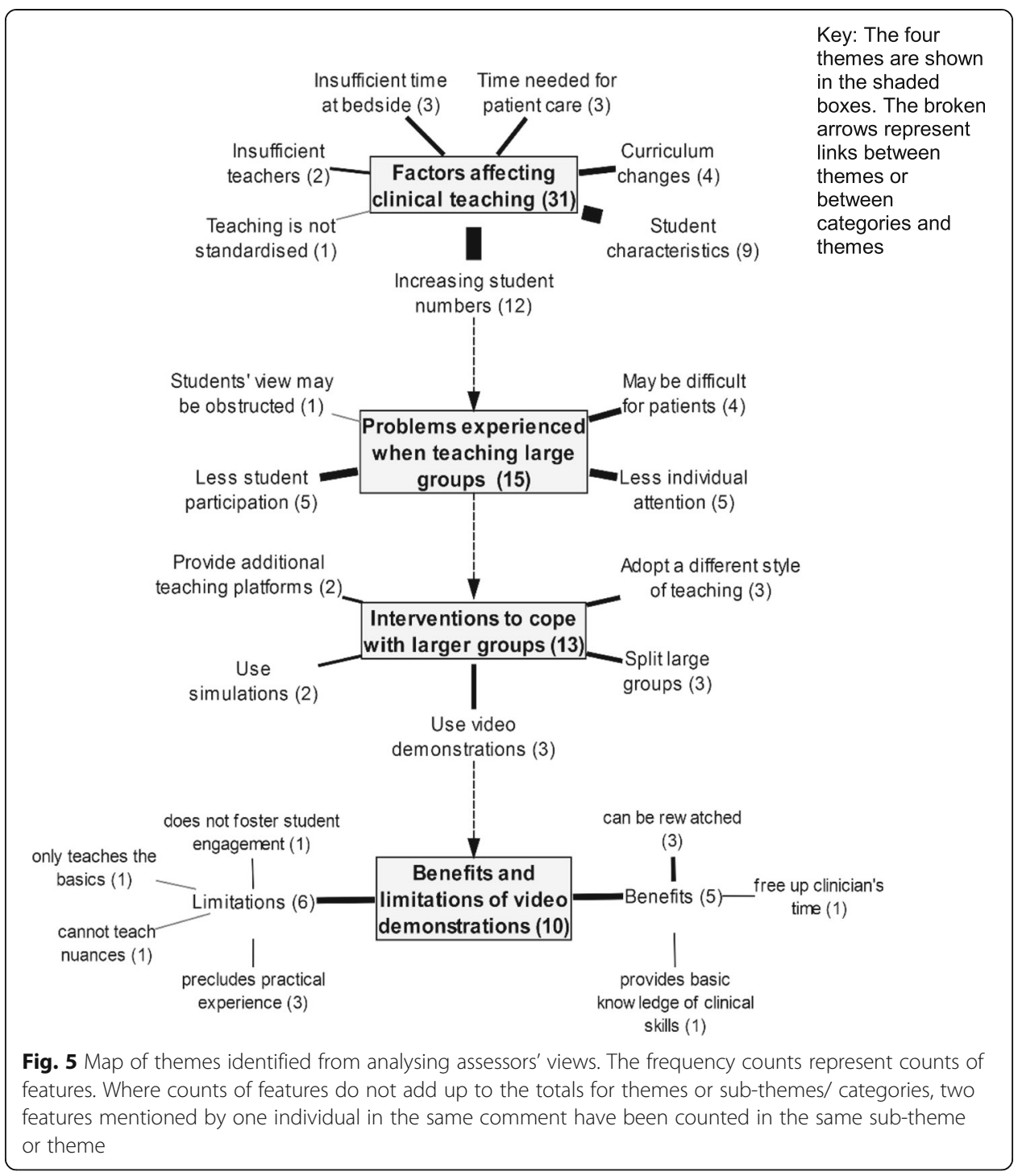

knowledge of the skills to be learned as both a benefit and a limitation (see Fig. 5). The other limitations of video demonstrations focused on the need for students to gain practical experience.

\section{Discussion}

To develop innovative solutions to the teaching challenges facing paediatric clinician educators in a low-resourced setting, videos demonstrating introductory paediatric clinical examination skills were recorded. The effectiveness of these videos was evaluated in a randomised trial that showed that the videos were non-inferior, within a $10 \%$ margin, to the bedside demonstration of clinical skills. There were no differences in the pass rates, or in the number of distinctions, between the two groups. The Belgian noninferiority study by Mpotos et al. (2011) also found video instruction not to be inferior to traditional teaching. During the focus group discussions, the assessors and students acknowledged that there was a need for an intervention to cope with the teaching of large groups of students around the bedside and described a number of benefits that 
videos could offer to alleviate the difficulties of teaching large groups. Both students and assessors emphasised that bedside teaching was an essential method to teach clinical skills; this type of teaching allows students to examine the child whilst allowing for real-time interactions between the clinician and student. Both groups of stakeholders acknowledged that video demonstrations could be useful for providing the basic knowledge before students attend the bedside tutorials, allowing educators to focus on the nuances of clinical examinations and the teaching of practical skills, and both groups felt that both methods were needed in our setting. Students in other studies have expressed similar views on the advantages offered by video instruction, including the flexibility of use it offers and the benefit of being able to prepare for teaching sessions, and also preferred video instruction to be used with lecturer demonstrations rather than replacing them (Hibbert et al., 2013; Kelly, Lyng, McGrath, \& Cannon, 2009). Blended learning, a combination of face-to-face and online learning, has been shown in other studies to the preferred method for incorporating videos into medical education (Choules, 2007; Hibbert et al., 2013; Hull, Chaudry, Prasthofer, \& Pattison, 2009).

Inadequate educational planning and government spending that does not keep pace with increasing student enrolment are likely to impact negatively on the quality of higher education ("African universities recruit too many students," 2017; Hornsby et al., 2013). More specifically, the impact of large class sizes could impact on the competency of medical graduates and, ultimately, on the quality of healthcare delivered in the country. The impact of class size on meaningful learning depends on the particular "discipline and/or the pedagogical needs of the learning environment" (Hornsby \& Osman, 2014, p. 714). The time-consuming and resource-intensive nature of clinical teaching (Bradley \& Postlethwaite, 2003) make it likely that large class sizes will affect the quality of teaching required to produce competent doctors. Additionally, the need for interpersonal interactions during clinical teaching, as pointed out by both educators and students in this study, is also likely to suffer. The social goal of the imperatives issued by the South African government to graduate more doctors was to address the doctor shortage in the country. However, while the need for more doctors is evident, an intervention is needed in educational institutions to ensure that increased student numbers do not negatively affect doctor competency. Hornsby et al. (2013) suggested that, in the absence of funding for additional resources, large classes in higher education provide opportunities for exploring innovative teaching methods. In this case, the use of video demonstrations for teaching clinical skills represents a radical change from the bedside teaching traditionally used at the academic hospitals affiliated with Wits University. It was thus necessary not only to compare the effectiveness of the video demonstrations to bedside teaching but also to explore students' and educators' perceptions of how video demonstrations could be used for clinical teaching.

It appears that both staff and students want video demonstrations to supplement rather than replace bedside teaching. Such a supplemental model could fit in well with models of how clinical skills are learned. Peyton's four-step model of learning a skill emphasises the importance of students initially observing a demonstration without being involved, to allow students to focus on learning the steps that make up the modelled or demonstrated behaviour (Walker \& Peyton, 1998). In Peyton's model, students only conduct an examination as the final step in learning a clinical skill. Similarly, in the cognitive model of sequential skill acquisition, observing a demonstrated behaviour 
is the first phase, culminating in a self-directed performance of the observed behaviour (Schunk \& Zimmerman, 1997; Zimmerman \& Kitsantas, 2002). Schunk and Zimmerman (1997) stressed the importance of students acquiring sufficient knowledge of the demonstrated behaviour before moving on to the second phase of learning a skill, that of imitating the observed behaviour. Video demonstrations could aid students with acquiring the basic knowledge that forms the foundation of learning clinical skills and allow them to do so at their own pace, as many times as they need to and at times convenient to them.

The potential benefits for learning of the supplemental model suggested by the stakeholders fail to address the central problem motivating the study, the limited resources available for teaching at $\mathrm{CHBAH}$, specifically the demands on clinician's time. Although the reusability of videos could ease clinicians' workload in the future, the initial costs of recording the videos, regarding both time and money, are likely to increase the clinicians' current burden. Educational interventions usually focus on educational benefits rather than, for example, the cost implications (Mustafa, 2018). However, costs are especially pertinent in low- and middle-income countries (Mustafa, 2018). The production cost for the video used in the study was recorded in 2015 at an estimated cost, expost facto, of $€ 1194.70$ (ZAR19 640). This amount includes the cost of the consultant's time, based on the hourly rate for a consultant in the public sector (14h $\mathrm{x}$ R760), including pre-shooting preparation and patient selection $(6 \mathrm{~h})$, and recording the video, including retakes $(8 \mathrm{~h})$; and the cost of a videographer to record and edit the video (18 $\mathrm{h} \times \mathrm{R} 500 / \mathrm{hr}$ ). In the case of CHBAH, the question is whether video demonstrations represent a cost-effective intervention if they are going to supplement bedside teaching. Although a formal cost analysis has not been undertaken, the initial investment required for the production of the videos is less than the annual costs paid to clinicians for their time spent teaching students. The case for the cost-effectiveness and scalability of the video demonstrations recorded at $\mathrm{CHBAH}$ is strengthened by the fact that the videos have been rolled out at the two other main teaching hospitals associated with Wits University, and that other South African universities have expressed an interest in using the video demonstrations.

The enduring nature and scalability and the cost-effectiveness of video demonstrations for teaching clinical skills reported in other studies (e.g. Hibbert et al., 2013) warrant further investigation into videos for supplementing bedside teaching in resourceconstrained settings, and into the cost-effectiveness of such a supplemental model of video usage. A potential area for research is to investigate the effects on learning of including interactivity in the design of the videos, which could foster student engagement. Another area is to assess the impact of integrating clinical videos with bedside teaching to optimise clinical training in low-resource settings.

The following limitations of this study are acknowledged. First, the defined non-inferiority margin of $10 \%$ may seem quite broad. All domains showed non-inferiority at $10 \%$, but would not be non-inferior at a margin of $5 \%$. Studies with larger sample sizes would be required to establish equivalence for narrower margins. However, the interval used was determined by study clinicians as appropriate, based on the mean pass mark obtained in fourteen paediatric end-of-block examinations in the 2 years preceding the study. It should also be noted that we converted the actual assessment marks into percentages in this analysis, for convenience. So the $10 \%$ margin equates to a 1-mark 
difference between the video and bedside teaching groups. A non-inferiority margin of less than 1-mark is not realistic since half-marks are not assigned for these clinical assessments. One mark was thus was the minimum difference that could be used. Second, although the study was adequately powered, the small sample size may limit its generalisability. However, the marks of students participating in the study suggest they were fairly typical of other medical students in the university, and the clinical teaching at CHBAH is similar to that of other teaching hospitals in the country. A final limitation of the study is that the separate facility in which the bedside tutorial was held offered comparatively better conditions than what students would commonly experience in the general paediatric ward. The better conditions may have increased the scores for the bedside teaching group compared to students taught under more typical conditions, but would not influence the conclusions from the non-inferiority analysis.

\section{Conclusion}

Based on the finding of noninferiority of the video teaching compared to the bedside teaching, and students and teachers perceptions that video demonstrations could be used to address the difficulties of teaching large groups of students, the results of the study suggest that video demonstrations of clinical skills may provide a cost-effective and scalable intervention in environments in which the pressure of numbers may be increasing. The findings from the study may have implications for policy decisions on the nature of clinical teaching at $\mathrm{CHBAH}$ and other resource-constrained hospitals in South Africa, and possibly in other low- and middle-income countries.

\section{Additional file}

Additional file 1: Assessment tool for clinical examination. (DOCX $15 \mathrm{~kb}$ )

\section{Abbreviations}

CHBAH: Chris Hani Baragwanath Academic Hospital; Cl: Confidence interval

\section{Acknowledgements}

The authors would like to acknowledge the students who participated in this study, the research intern who conducted the focus group discussions, and the paediatricians who agreed to assist with the study should the need have arisen.

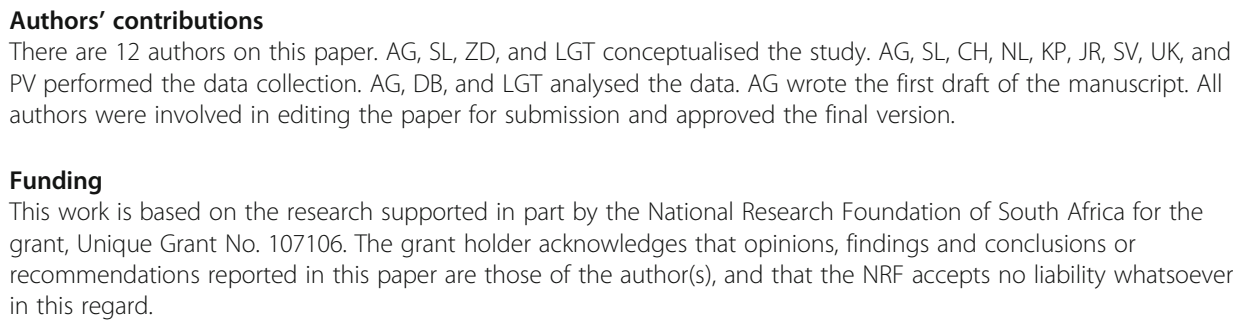

Availability of data and materials

The datasets generated and/or analysed during the current study are available from https://doi.org/10.17605/OSF.IO/R5 $8 \mathrm{JS}$ at the repository handle https://osf.io/r58j. Any request for de-identified sample data will be considered by the data access committee on a case-by-case basis.

Competing interests

The authors declare that they have no competing interests.

\section{Author details}

${ }^{1}$ Centre for Health Science Education, Faculty of Health Sciences, University of the Witwatersrand, 29 Princess of Wales

Terrace, Parktown, Johannesburg 2193, South Africa. ${ }^{2}$ Centre for Health Policy, School of Public Health, Faculty of 
Health Sciences, University of the Witwatersrand, 27 St Andrews Road, Parktown, Johannesburg 2193, South Africa. ${ }^{3}$ Office of Teaching and Learning, Faculty of Health Sciences, University of the Witwatersrand, 29 Princess of Wales Terrace, Parktown, Johannesburg 2193, South Africa. ${ }^{4}$ Department of Paediatrics \& Child Health, Chris Hani Baragwanath Hospital, 26 Chris Hani Rd, Diepkloof, Johannesburg 1864, South Africa. ${ }^{5}$ Perinatal HIV Research Unit, Chris Hani Baragwanath Hospital, 26 Chris Hani Rd, Diepkloof, Johannesburg 1864, South Africa. ${ }^{6}$ Present Address: School of Medicine, Sefako Makgatho Health Sciences University, Molotlegi Street Ga-Rankuwa, Registry P.O Box 60. Medunsa, Pretoria, Gauteng 0204, South Africa.

Received: 6 February 2019 Accepted: 10 July 2019

Published online: 10 September 2019

\section{References}

African universities recruit too many students. (2017, April 12). The Economist. Retrieved from https:/www.economist.com/ middle-east-and-africa/2017/04/12/african-universities-recruit-too-many-students

Barbour, R. S. (2001). Checklists for improving rigour in qualitative research: A case of the tail wagging the dog? British Medical Journal, 322(1), 1115-1117.

Bradley, P., \& Postlethwaite, K. (2003). Setting up a clinical skills learning facility. Medical Education, 37(Suppl 1), 6-13. https:// doi.org/10.1046/j.1365-2923.37.s1.11.x

Braun, V., \& Clarke, V. (2013). Successful qualitative research: A practical guide for beginners. London: Sage Publications Ltd.

Choules, A. (2007). The use of elearning in medical education: A review of the current situation. Postgraduate Medical Journal, 83(978), 212-216. https://doi.org/10.1136/pgmj.2006.054189.

Cook, D. A., \& Hatala, R. (2015). Got power? A systematic review of sample size adequacy in health professions education research. Advances in Health Sciences Education: Theory and Practice, 20(1), 73-83. https://doi.org/10.1007/s10459-014-95 09-5.

Coovadia, H., Jewkes, R., Barron, P., Sanders, D., \& McIntyre, D. (2009). The health and health system of South Africa: Historical roots of current public health challenges. The Lancet, 374(9692), 817-834. https://doi.org/10.1016/S0140-6736(09)60951-X.

Craze, J., \& Hope, T. (2006). Teaching medical students to examine children. Archives of Disease in Childhood, 91(12), 966-968. https://doi.org/10.1136/adc.2005.092502.

Creswell, J. W. (2014). Research design: Quantitative, qualitative, and mixed methods approaches, (4th ed., ). Thousand Oaks: Sage Publications Inc

Fraenkel, J. R., Wallen, N. E., \& Hyun, H. H. (2012). How to design and evaluate research in education, (8th ed., ). New York: McGraw-Hill.

Frenk, J., Chen, L., Bhutta, Z. A., Cohen, J., Crisp, N., Evans, T., ... Zurayk, H. (2010). Health professionals for a new century: Transforming education to strengthen health systems in an interdependent world. The Lancet, 376(9756), 1923-1958. https://doi.org/10.1016/S0140-6736(10)61854-5.

Greene, C., Morland, L., Durkalski, V., \& Frueh, B. (2008). Noninferiority and equivalence designs: Issues and implications for mental health research. Journal of Traumatic Stress, 21(5), 433-439. https://doi.org/10.1002/jts.20367.

Hibbert, E. J., Lambert, T., Carter, J. N., Learoyd, D. L., Twigg, S., \& Clarke, S. (2013). A randomized controlled pilot trial comparing the impact of access to clinical endocrinology video demonstrations with access to usual revision resources on medical student performance of clinical endocrinology skills. BMC Medical Education, 13(1), 135. https://doi.org/10.11 86/1472-6920-13-135.

Hoffman, K. G., \& Donaldson, J. F. (2004). Contextual tensions of the clinical environment and their influence on teaching and learning. Medical Education, 38(4), 448-454. https://doi.org/10.1046/j.1365-2923.2004.01799.x.

Hornsby, D., \& Osman, R. (2014). Massification in higher education: Large classes and student learning. Higher Education, 67(6), 711-719. https://doi.org/10.1007/s10734-014-9733-1.

Hornsby, D., Osman, R., \& De Matos-Ala, J. D. E. (2013). Teaching large classes - Quality education despite the odds. In D. J. Hornsby, R. Osman, \& J. de Matos-ALa (Eds.), Large-class pedagogy: Interdisciplinary perspectives for quality higher education (pp. 7-18). Stellenbosch: Sun Press.

Hull, P., Chaudry, A., Prasthofer, A., \& Pattison, G. (2009). Optimal sequencing of bedside teaching and computer-based learning: A randomised trial. Medical Education, 43(2), 108-112. https://doi.org/10.1111/j.1365-2923.2008.03261.x.

Hurtubise, L., Martin, B., Gilliland, A., \& Mahan, J. (2013). To play or not to play: Leveraging video in medical education. Journal of Graduate Medical Education, 5(1), 13-18. https://doi.org/10.4300/JGME-05-01-32.

Jeffries, P. R. (2001). Computer versus lecture: A comparison of two methods of teaching oral medication administration in a nursing skills laboratory. The Journal of Nursing Education, 40(7), 323-329.

Johnson, R. B., Onwuegbuzie, A. J., \& Turner, L. A. (2007). Toward a definition of mixed methods research. Journal of Mixed Methods Research, 1(2), 112-133.

Jones, P. (2010). Stata module to estimate sample size for randomized controlled trials,. Retrieved January 10, 2017, from https://ideas.repec.org/c/boc/bocode/s457150.html

Kelly, M., Lyng, C. McGrath, M., \& Cannon, G. (2009). A multi-method study to determine the effectiveness of, and student attitudes to, online instructional videos for teaching clinical nursing skills. Nurse Education Today, 29(3), 292-300. https:/ doi.org/10.1016/..nedt.2008.09.004.

Kneebone, R. (2005). Evaluating clinical simulations for learning procedural skills: A theory-based approach. Academic Medicine, 80(6), 546-553.

Knowles, C., Kinchington, F., Erwin, J., \& Peters, B. (2001). A randomised controlled trial of the effectiveness of combining video role play with traditional methods of delivering undergraduate medical education. Sexually Transmitted Infections, 77(5), 376-380. https://doi.org/10.1136/sti.77.5.376.

Krippendorff, K. (2013). Content analysis: An introduction to its methodology, (3rd ed., ). Thousand Oaks: Sage Publications, Inc Lake, F., \& Hamdorf, J. (2004). Teaching on the run tips 5: Teaching a skill. Medical Journal of Australia, 181, 327-328.

Maudsley, G., \& Strivens, J. (2000). Promoting professional knowledge, experiential learning and critical thinking for medical students. Medical Education, 34(7), 535-544. https://doi.org/10.1046/j.1365-2923.2000.00632.x. 
Mayosi, B. M., Ch, B., Phil, D., Benatar, S. R., Ch, B., \& Med, D. S. (2014). Health and health care in South Africa - 20 years after Mandela. The New England Journal of Medicine, 371(14), 1344-1353. https://doi.org/10.1056/NEJMsr1405012.

Mayosi, B. M., Flisher, A. J., Lalloo, U. G., Sitas, F., Tollman, S. M., Bradshaw, D., ... Africa, S. (2009). The burden of noncommunicable diseases in South Africa. The Lancet, 6736(09), 1-14. https://doi.org/10.1016/S0140-6736(09)61087-4.

McKeachie, W. J. (1980). Class size, large classes, and multiple sections. Academe, 66(1), 24-27.

McMillan, J. H., \& Schumacher, S. (2010). Designing qualitative research: Evidence-based inquiry. Research in education: Evidencebased inquiry, (7th ed., ). New Jersey: Pearson Education, Inc.

Michels, M., Evans, D., \& Blok, G. (2012). What is a clinical skill? Searching for order in chaos through a modified Delphi process. Medical Teacher, 34, e573-e581.

Mpotos, N., Lemoyne, S., Calle, P. A., Deschepper, E., Valcke, M., \& Monsieurs, K. G. (2011). Combining video instruction followed by voice feedback in a self-learning station for acquisition of basic life support skills: A randomised noninferiority trial. Resuscitation, 82(7), 896-901. https://doi.org/10.1016/j.resuscitation.2011.02.024.

Mustafa, N. (2018). Cost-effectiveness analysis: Educational interventions that reduce the incidence of HIV/AIDS infection in Kenyan teenagers. International Journal of Educational Development, 62, 264-269. https://doi.org/10.1016/j.jjedudev.2018.06.001.

Piaggio, G., Elbourne, D. R., Altman, D. G., Pocock, S. J., \& Evans (2006). Reporting of noninferiority and equivalence randomized trials: An extension of the CONSORT statement. Journal of the American Medical Association, 295(10), 11521160. https://doi.org/10.1001/jama.2012.87802.

Sadideen, H., \& Kneebone, R. (2012). Practical skills teaching in contemporary surgical education: How can educational theory be applied to promote effective learning? American Journal of Surgery, 204(3), 396-401. https://doi.org/10.1016/j.amjsurg.2 011.12.020.

Schunk, D. H., \& Zimmerman, B. J. (1997). Social origins of self-regulatory competence. Educational Psychologist, 32, $195-208$. https://doi.org/10.1207/s15326985ep3204.

Schwerdtfeger, K., Wand, S., Schmid, O., Roessler, M., Quintel, M., Leissner, K. B., \& Russo, S. G. (2014). A prospective, blinded evaluation of a video-assisted '4-stage approach' during undergraduate student practical skills training. BMC Medical Education, 14(1), 104. https://doi.org/10.1186/1472-6920-14-104.

Singley, M., \& Anderson, J. (1989). The transfer of cognitive skill. Cambridge: Harvard University Press.

South African National Department of Health. (2010). Negotiated Service Delivery Agreement 2010-2014.

Tolsgaard, M. G., \& Ringsted, C. (2014). Using equivalence designs to improve methodological rigor in medical education trials. Medical Education, 48(2), 220-221. https://doi.org/10.1111/medu.12313.

Walker, M., \& Peyton, J. (1998). Teaching in theatre. In J. Peyton (Ed.), Teaching and learning in medical practice, (pp. 171-180). Heronsgate Rickmansworth, Herts: Manticore Europe Itd.

Wouters, P., Tabbers, H. K., \& Paas, F. (2007). Interactivity in video-based models. Educational Psychology Review, 19(3), $327-342$. https://doi.org/10.1007/s10648-007-9045-4.

Zimmerman, B. J., \& Kitsantas, A. (2002). Acquiring writing revision and self-regulatory skill through observation and emulation. Journal of Educational Psychology, 94(4), 660-668. https://doi.org/10.1037//0022-0663.94.4.660.

\section{Publisher's Note}

Springer Nature remains neutral with regard to jurisdictional claims in published maps and institutional affiliations.

\section{Submit your manuscript to a SpringerOpen ${ }^{\circ}$ journal and benefit from:}

- Convenient online submission

- Rigorous peer review

- Open access: articles freely available online

- High visibility within the field

- Retaining the copyright to your article

Submit your next manuscript at $\boldsymbol{\nabla}$ springeropen.com 